\title{
About "Origin and evolution of the free radical theory of aging: a brief personal history, 1954-2009”
}

\author{
Denham Harman
}

Received: 13 October 2009/Accepted: 14 October 2009/Published online: 25 October 2009

(C) Springer Science+Business Media B.V. 2009

My short paper, "Origin and evolution of the free radical theory of aging: a brief personal history, 1954-2009" by myself was recently published in Biogerontology. In this paper I inadvertently failed to make clear the difference between the research fields of oxygen toxicity and aging. I indicated that Drs. Rebeca Gershman and Daniel Gilbert were reported to apparently equate "oxygen toxicity" with "aging." Although free radicals are involved in both fields (see
Harman, D., Ann. N.Y. Acad. Sci., 1067: 10-21, 2006; pages 16-17), time is required to manifest the complex product attributed to aging. Further, the research fields of aging and oxygen toxicity differ clinically. Oxygen toxicity is of relatively little importance to "man," whereas aging is of major importance. Judging from the literature concerned with both aging and oxygen toxicity, this difference may not be appreciated by some.

D. Harman $(\bowtie)$

Department of Medicine, University of Nebraska Medical

Center, Omaha, NE 68198-4416, USA

e-mail: toconnor@unmc.edu 